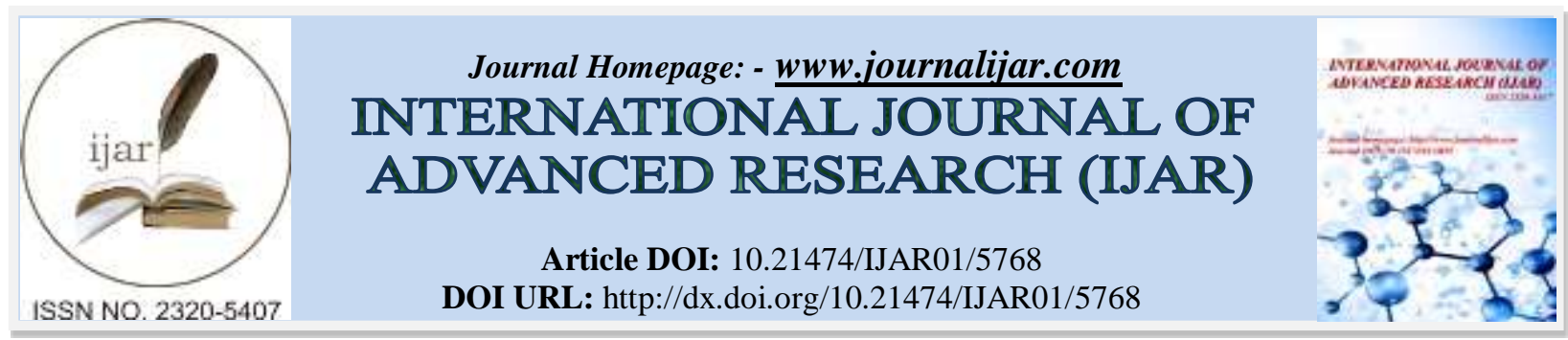

RESEARCH ARTICLE

\title{
CHARACTERISTICS OF ANTIMICROBIAL PEPTIDES ORIGINATED FROM INVERTEBRATES INCLUDING INSECT.
}

\author{
Sam Woong Kim ${ }^{1}$, Woo Young Bang ${ }^{2}$, Tae Wan Kim ${ }^{1}$, Seung-Ho Jeon ${ }^{3}$, Chi Won Noh ${ }^{4}$, Chae Won Lee ${ }^{2}$ and \\ "Il-Suk Kim"
}

1. Department of Animal Resources Technology, Gyeongnam National University of Science and Technology, Gyeongnam, 52725, South Korea.

2. National Institute of Biological Resources (NIBR), Environmental Research Complex, Incheon 22689, South Korea.

3. Department of Agronomy \& Medicinal Plant Resources, Gyeongnam National University of Science and Technology, Jinju, 52725, South Korea.

4. Gyeongsangnam-do Agricultural Research \& Extension Services, Jinju, 52733, South Korea.

\section{Manuscript Info}

Manuscript History

Received: 04 September 2017

Final Accepted: 06 October 2017

Published: November 2017

Key words:-

AMPs, antiactivity, insect, invertebrate, net charge, peptides.

\section{Abstract}

Most AMPs discovered in invertebrates were found in arthropods including insect, and antibacterial activity was discovered by specifically high frequency against Gram positive bacteria. The length of peptides discovered the highest amount in 31 40 peptides, and it maintained comparatively higher levels in 11 50 peptides. The secondary structure of peptides showed the highest value in alphahelix, but very lower amounts in beta-sheet and coil form. As net charge was ranged from +1 to +7 , it was observed to have a net charge slightly higher than general AMPs. Aliphatic index was observed to have the largest amount between 70 and 80, which more than half of the peptides were found to form a stable structure. Therefore, it is suggested that AMPs found in invertebrates have characteristics similar to AMPs discovered in all the organisms.

Copy Right, IJAR, 2017,. All rights reserved.

\section{Introduction:-}

All the organisms secrete primary protective substances for their own defense. One of such protective substances is antimicrobial peptides (AMPs). It is known that AMPs play a role as an important protective tool in insect to have not an acquired defensive mechanism, and have the function to induce AMPs as a defense substance against externally invading organisms. Cellular and humoral innate immune mechanisms are retained in animal kingdom (Lazzaro, 2008), and it is regulated by a signal pathway activated by various stimuli. Cellular immune responses of insect induce phagocytosis, nodulation and encapsulation (Schmidt and Theopold, 2001; Nappi et al., 2004; Lamprou et al., 2005; Sideri et al., 2008), whereas humoral response is associated with pro-phenol oxidase proteolytic cascade (Bulet et al., 2008; Bulet and Stocklin, 2005).

AMPs are generally composed of cationic substances in low molecular weight, and perform their functions by destroying cell membrane of microorganism (Bulet and Stocklin, 2005). The function of AMPs is not limited to direct killing of microorganisms, but related with action of immunomodulation and with regulation of endosymbiotic bacteria (Easton et al., 2009: Login et al., 2011). AMPs are classified within three groups according 
to structure and nonspecific richness of specific amino acids: (1) alpha-helical peptides lacking cysteine residues; (2) beta-sheet globular structure stabilized by intramolecular disulfide bridges; and rich peptides to maintain a large proportion of nonspecific proline or glycine resides.

In this review, as we investigated various properties of invertebrate and arthropoda including insect-derived AMPs discovered to date, we supported a basic data to classify the characteristics of insect-derived AMPs.

\section{Datadase for AMPs mining:-}

AMPs used in this review were analyzed by 702 peptides (Apr 2017) registered in InverPep (http://ciencias.medellin.unal.edu.co/).

\section{Classification of AMPs according to activity and their physical properties:-}

Most of the 702 AMPs studied in invertebrates have been found by arthropoda including insect. The number of AMPs discovered in Arthropoda was 583 AMPs and equivalent to 83\% among total AMPs (Fig. 1). In the remaining phylum, Mollusca, Nematoda and Chordata showed 6.8, 3.3 and 3.0\%, respectively. Arthropoda is included by insects, spiders and crustaceans, and $80 \%$ or more of existing species are included in arthropod animals.

The antimicrobial activity was accounted for the highest proportion as 520 AMPs against Gram positive bacteria (Fig. 2). The next activity against fungi was kept high amount as 202 AMPs. However, the activity against Gram negative bacteria was very low as 65 AMPs. In an uninduced state, although the antimicrobial activity of insect AMPs was detected by high numbers against Gram positive bacteria, it was hardly detected in Gram negative bacteria (unpublished data). However, when compared to AMPs that are common in nature to have low frequency activity of Gram positive bacteria (Yanmei et al., 2012), AMPs in insects maintain very specific phenomena. While such aspects are surviving in nature, it is assumed that insects are well-exposed to pathogenic Gram positive bacteria, but well-unexposed to Gram negative bacteria.

AMPs originated from insects were found to have not only antibacterial and antifungal properties but also parasite, insect, virus, cancer cell and chemostatic activities. These activities were observed at a very low frequency when compared to antibacterial and antifungal properties, but presented by the possibility to confer its various functionalities.

Generally, well-known AMPs are composed of sizes of $10 \mathrm{kDa}$ or less, and it is known that they were composed of almost 20 to 40 residues (Dimopoulos et al., 1997; Reddy et al., 2004; Wang, 2013). The number of peptides observed in this review was high frequencies between 11 20 and 31 40 residues (Fig. 3). Even though numbers were observed by relatively low amounts between 21 and 30 residues, it is assumed that peptides corresponding to between 11 and 40 residues are excavated by more amounts as AMPs. This result shows a pattern that coincides with the high number of generally found AMPs between 11 and 40 residues (Wang, 2013; APD by July 2017). The number of AMPs at 40 residues or more tended to decrease step by step. Therefore, it is presumed to exhibit a common feature that AMPs in insects maintain higher amount in 11 to 40 peptides.

The secondary structures of insect AMPs were accounted for the most proportion as $376(53.6 \%)$ in the unknown structural peptides. The alpha-helix was the highest ratio at 128 peptides (18.2\%) among the known structures, but ciclopeptide and coil form were observed at low frequencies (Fig. 4). Beta-sheet of 22 peptides was observed less frequent ratio than that of rich form. From such a result, it is suggested that alpha-helix maintains an optimal structure to induce antimicrobial action on membrane. However, it is presumed that beta-sheet and coil form are relatively difficult to show their functions via interaction on membrane. On the other hand, it is presumed that ciclopeptide is less frequent due to difficulty in forming the structure itself.

\section{Classification depending on chemical properties:-}

Net charge of AMPs in insect showed all high proportions from +1 to +7 (Fig. 5). This result is somewhat different from the aspect shown in the net charge of generally discovered AMPs. In the general case, net charge displays high values in +1 to +4 (Wang, 2013; APD by July 2017). Therefore, it is assumed that similar levels from +1 to +7 are specific phenomenon of AMPs in invertebrate.

Wide distribution of net positive charge also induced wide distribution of pI value (Fig. 6). The pI values in this review showed a high distribution from 8 to 12. Aliphatic index showed the highest numerical value between 70 and 
80, showed a tendency to decrease gradually around this region (Fig. 7). Overall peptides have been shown to maintain a relatively high structural stability with a numerical value of 55 peptides or more above $70 \%$ in aliphatic index.

The residues of hydrophobic amino acids maintained the highest value between 30 and 40\%, whereas less than 10\% or more than $60 \%$ showed low frequencies (Fig. 8). In addition, the frequency of commonly known hydrophobic resides in AMPs presented the similar trend as 40 to 60\% (Wang, 2013; APD by July 2017). It is assumed that these phenomena have a deep connection with net charge and $\mathrm{pI}$ value.

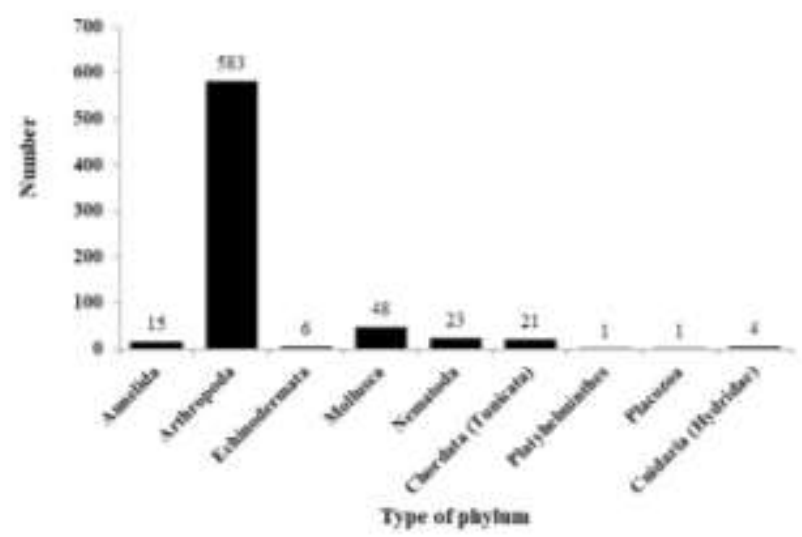

Fig. 1:- AMPs originated from invertbrate. Total AMPs employed for this study was 702 peptides obtained from InverPep database.

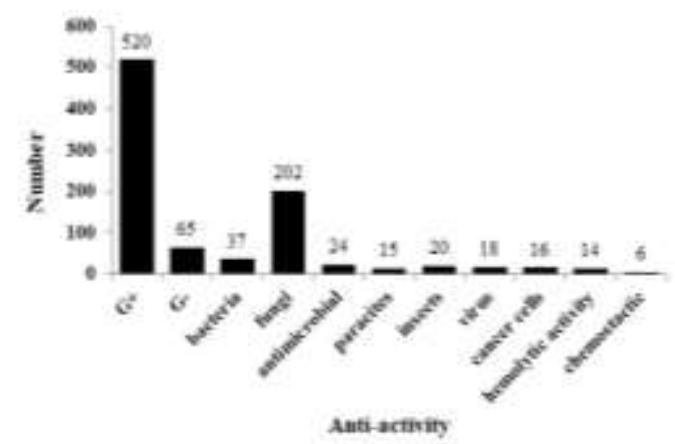

Fig. 2:- Functional classification of AMPs originated from invertbrate. Some AMPs appeared in partially overlapped activities such as antimicrobial activity including antibacterial and antifungal activities. These were indicated by separated number for each activity.

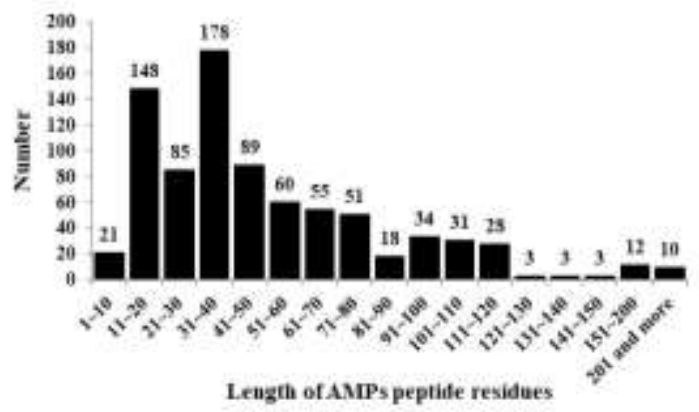

Fig. 3:- Classification of invertbrate AMPs depending on peptide residues. AMPs were classified in 10 units. However, 151 to 200 and above 201 were summarized to be tied up together due to small amount in each section. 


\begin{tabular}{|c|c|c|c|c|c|c|c|c|c|c|}
\hline & beta & cklypentale & $\mathrm{ced}$ & $\begin{array}{c}\text { uentue bih } \\
\text { and beta }\end{array}$ & beis & exhelistiess & Fodudty lakin & Eh & adknowi & 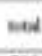 \\
\hline Sormelen & 22 & 1 & 1 & 51 & 121 & 2 & 23 & 91 & 376 & 703 \\
\hline Penced (9v) & 31 & 0.1 & 0.1 & (3) & 112 & 03 & 33 & 130 & 93.6 & 100 \\
\hline
\end{tabular}

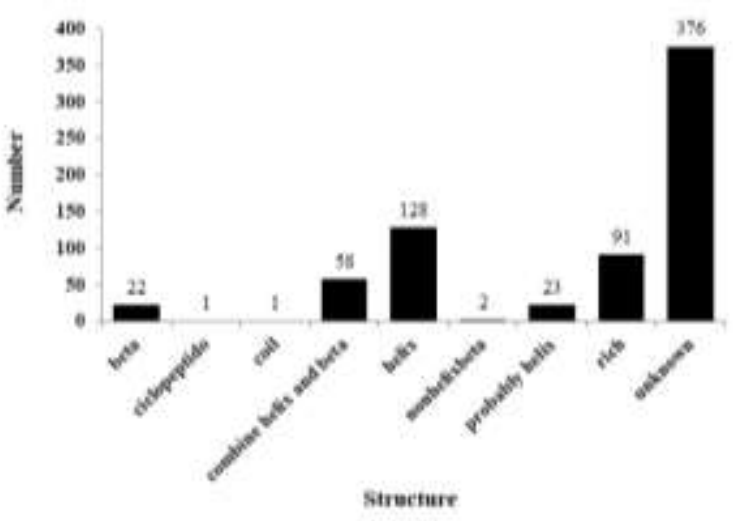

Fig. 4:- Classification of invertbrate AMPs depending on peptide structure. AMPs were classified depending on secondary structure of peptide.

\begin{tabular}{|c|c|c|c|c|c|c|c|c|c|c|c|c|c|c|}
\hline uv & ss & 5.40 & - & ens 1 & $1<-12$ & $2 \times-53$ & $3-14$ & $4<-35$ & $\operatorname{sen} 56$ & $6-57$ & $7<-53$ & $1=-39$ & $9-510$ & teisel \\
\hline Hatin (96) & 16 & 31 & 21 & 100 & 10.8 & 130 & 119 & 100 & 129 & 97 & 31 & 3.3 & 34 & 100 \\
\hline
\end{tabular}

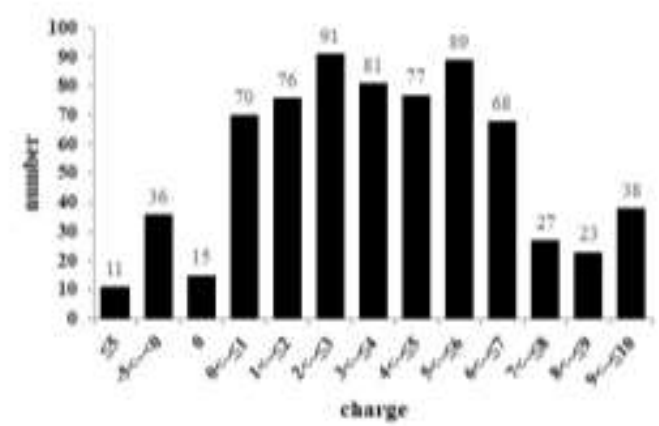

Fig. 5:- Classification of invertbrate AMPs depending on Net charge. AMPs were classified depending on net charge.

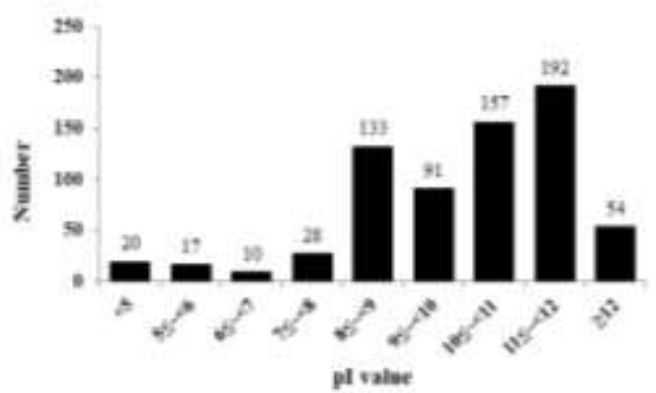

Fig. 6:- Classification of invertbrate AMPs depending on pI value. AMPs were classified depending on pI value. 


\begin{tabular}{|c|c|c|c|c|c|c|c|c|c|c|c|c|c|c|c|c|c|c|}
\hline Rang & de & $16 s-10$ & $20 s=90$ & $36 s-16$ & $48 s-96$ & $54=-60$ & 60 & $\mathrm{~T}_{\mathrm{s}}-\mathrm{at}$ & $\omega_{s}-90$ & $00 s-918$ & $100 s=-116$ & $10 s-426$ & $20 s-196$ & $130 s-44$ & $40 s-450$ & $496 s-200$ & 2260 & teeal \\
\hline Rasis (46) & is & 24 & 10 & (1) & 90 & 90 & S.t. & 12.1 & 11 & 25 & $9 A$ & $M$ & 20 & 20 & 33 & ts & 10 & 100 \\
\hline
\end{tabular}

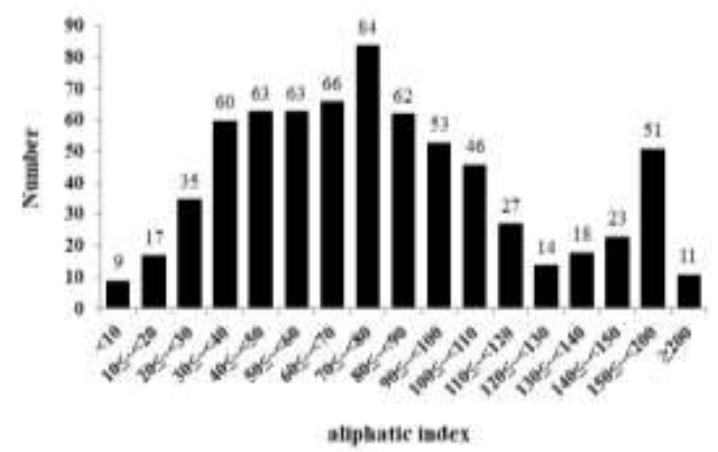

Fig. 7:- Classification of invertbrate AMPs depending on aliphatic index. AMPs were classified depending on aliphatic index.

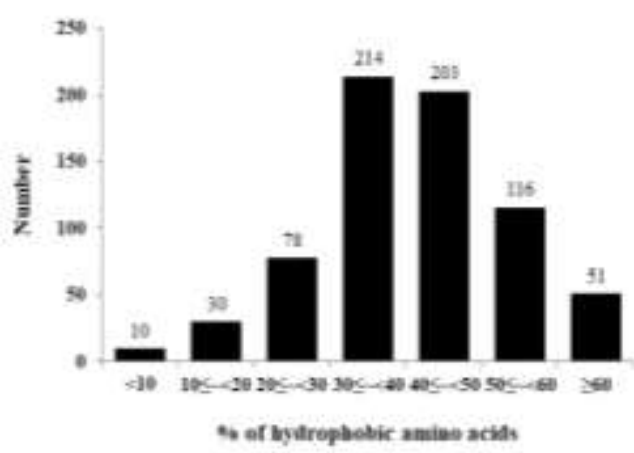

Fig. 8:- Classification of invertbrate AMPs depending on hydrophobic amino acids. AMPs were classified depending on hydrophobic amino acids.

\section{Conclusions:-}

Most of AMPs found in invertebrate were found in arthropod including insect, and to be highly specific for Gram positive bacteria. AMPs showed the highest values by 11 to 40 in length, alpha helix in secondary structure, +1 to +7 in net charge and 70 to 80 in aliphatic index. Therefore, we suggest that AMPs found in invertebrate maintain similar characteristics to general AMPs.

\section{Acknowledgment:-}

This work was supported by Gyeongnam National University of Science and Technology Grant 2017.

\section{References:-}

1. Bulet P, Hetru C, Dimarcq JL, Hoffmann D. 1999. Antimicrobial peptides in insects structure and function. Dev. Comp. Immunol. 23: 329-344.

2. Bulet P, Stöcklin R. 2005. Insect antimicrobial peptides: Structures, properties and gene regulation. Protein Pept. Lett. 12: 3-11.

3. Dimopoulos G, Richman A, M"uller HM, Kafatos FC. 1997. Molecular immune responses of the mosquito Anopheles gambiae to bacteria and malaria parasites. Proc Natl Acad Sci USA, 94: 11508-11513.

4. Easton, DM., Nijnik, A., Mayer, ML., Hancock, RE., 2009. Potential of immunomodulatory host defense peptides as novel anti-infectives. Trends Biotechnol. 27: 582-590.

5. Lamprou I, Tsakas S, Theodorou GL, Karakantza M, Lampropoulou M, Marmaras VJ. 2005. Uptake of LPS/E. coli/latex beads via distinct signalling pathways in medfly hemocytes: The role of MAP kinases activation and protein secretion. Biochim. Biophys. Acta. 1744: 1-10. 
6. Lazzaro BP. 2008. Natural selection on the Drosophila antimicrobial immune system. Curr. Opin. Microbiol. 11: 284-289.

7. Li Y, Xiang Q, Zhang Q, Huang Y, Su Z. 2012. Overview on the recent study of antimicrobial peptides: origins, functions, relative mechanisms and application. Peptides. 37 (2): 207-215.

8. Login, FH, Balmand, S, Vallier, A, Vincent-Monégat, C, Vigneron, A, Weiss-Gayet, M, Rochat, D, Heddi, A 2011. Antimicrobial peptides keep insect endosymbionts under control. Science 334: 362-365.

9. Nappi AJ, Kohler L, Mastore M, Funzionale B. 2004. Signaling pathways implicated in the cellular innate immune responses of Drosophila. Invertebrate Surviv. J. 1: 5-33.

10. Reddy KV, Yedery RD, Aranha C. 2004. Antimicrobial peptides: premises and promises. Int J Antimicrob Agents. 24(6): 536-547.

11. Schmidt O, Theopold U, Strand M. 2001. Innate immunity and its evasion and suppression by hymenopteran endoparasitoids. Bioessays. 23: 344-351.

12. Sideri M, Tsakas S, Markoutsa E, Lampropoulou M, Marmaras VJ. 2008. Innate immunity in insects: Surfaceassociated dopa decarboxylase-dependent pathways regulate phagocytosis, nodulation and melanization in medfly haemocytes. Immunology. 123: 528-537.

13. The Antimicrobial Peptide Database. http://aps.unmc.edu/AP/facts.php

14. Wang G. 2013. Database-Guided Discovery of Potent Peptides to Combat HIV-1 or Superbugs. Pharmaceuticals (Basel), 6 (6): 728-758. 